\title{
Rusya'da Taşnaksutun İddianamesi Dosyasında Yer Alan Şifreli Kelimeler ve Deşifresi
}

\author{
Enciphered Words Found in the Russian Files of Indictment on the \\ Dasnaksutyun And These words Deciphered
}

\begin{abstract}
Şahin DOĞAN *
Öz: 1890 yılında Tiflis’te kurulmuş olan Taşnaksutun Komitesi, Osmanlı Devleti'nde Ermeni olaylarının ortaya çıkmasında en önemli rol oynamış komitelerden biridir. I. Dünya Savaşı arifesinde ve sırasında ise bu komite Ermeniler üzerinde en etkili komite durumuna gelmişti. Taşnaksutun hem Rusya hem de Osmanlı Devleti içerisinde aktif bir şekilde örgütlenmiş ve yasal olmayan gizli bir komiteydi. İşte bu makalede, araştırmacıların konuya ilişkin Rus arşivlerinde çalışırken karşılaşabilecekleri Ermeni İhtilal Komitesi Taşnaksutun'un Çarlık Rusya mahkemelerine konu olan dava dosyalarında karşılaşılan gizli kişi, yer ve diğer şifreli kelimeler ile Rus makamlarınca yapılan deşifreleri verilerek değerlendirilmiştir.
\end{abstract}

Anahtar sözcükler: Taşnaksutun Komitesi, Şifreli Kelimeler, Ermeni Komiteleri, Rusya

\begin{abstract}
The Dashnaksutun Committee, which was established in 1890 in Tbilisi, was a committee that played an important role in the emergence of the Armenian incidents, together with other Armenian Committees in the Ottoman State. On the eve of the First World War and during its course, this committee became the most effective one of the Armenians. Dashnaksutun was an actively organized, secret and illegal committee both in Russia and in the Ottoman State. In this article the enciphered names of people, places and other enciphered words found in the Dashnaksutun Armenian Revolution Committee case files that were investigated by the tsarist Russian courts are given, together with their decipherment made by the Russian authorities.
\end{abstract}

Keywords: Dashnaksutun Committee, Enciphered Words, Armenian Committees, Russia

Ermeni sorununa ilişkin araştırmalar ülkemizde özellikle son 20 yılda oldukça yoğun bir şekilde artmış ve belli bir olgunluğa ulaşmışır. Ülkemiz üniversitelerinde düzenlenen sempozyumlar, başta tarihçiler ve uluslararası ilişkiler akademisyenlerinin kaleme aldıkları makaleler, kitaplar ve başvuru eserleri, doktora ve yüksek lisans tezleri, ayrıca Başbakanlık Osmanlı Arşivi'nin arşiv belgeleri yayınları göz önüne alınırsa hem nicelik hem de nitelik olarak belli bir düzey yakalanmıştır. Bu çalışmaların büyük bir kısmı özellikle Başbakanlık Osmanlı Arşivi belgelerine dayalı olmakla birlikte, İngiliz, Fransız, Amerikan ve Rus arşiv ve kaynaklarının da kullanılarak yazılan akademik çalışmaların Ermeni sorunu literatüründe yer edindiğini görüyoruz. Bu ülkeler içerisinde özellikle Rus arşiv ve kaynakları konuyla ilişkili akademik çevrelerin hep odak noktasında olmuş ve önem arz etmiştir. Böyle bir durum oluşmasında, Rusya' da da büyük bir Ermeni nüfusun yaşaması, Rusya Ermenileri'nin Osmanlı Ermenileri üzerinde etkili olma-

\footnotetext{
* Doç. Dr., Akdeniz Üniversitesi, Edebiyat Fakültesi, Tarih Bölümü, Antalya. sahindogan@akdeniz.edu.tr
} 
ları, Ermeni olaylarının ortaya çıkmasında büyük rol oynayan çeşitli Ermeni komitelerinin daha ziyade Rus Ermenileri tarafından kurulmuş olmaları, Ermeni olaylarının yaşandığı bölgelere Rusya'nın sınır olması ve I. Dünya Savaşı'nda bu bölgelerin bir müddet Rus işgali altına girmesi gibi nedenlerden ötürü konuya ilişkin Rus arşivlerinde önemli belgelerin bulunması büyük bir rol oynamıştır. Ayrıca Çarlık Rusya'nın yıkılarak Sovyet iktidarının kurulma sürecinde iktidara gelen Bolşevik döneme ait belgelerin bu meseleye ilişkin daha gerçeklere uygun bilgiler içermesi de bu hususta önemli bir yere sahiptir. (Yabancı arşiv ve kaynaklara dayalı birçok değerli çalışma olmakla birlikte özellikle TTK'nın yayınları arasında çıkmış olan bazı örnekler şunlardır: Şimşir 1989-1990; Dilan 2005; Bashanov 2013 vd.; Sonyel 2014).

$\mathrm{Bu}$ bağlamda bu makalede, özellikle son y1llarda Rus arşivlerinde Ermeni meselesi üzerine çalışan araştırmacıların, araştırmaları sırasında belgelerde karşılaşabilecekleri Ermeni ihtilal komitesi Taşnaksutun iddianamesi dosyasındaki, komitenin kullandığı bazı şifreli kişi, yer isimleri ve diğer şifreli kelimelerin Rus arşiv belgesine dayanarak yayınlanmasının faydalı olacağ 1 düşünülmüştür.

Bilindiği üzere Taşnaksutun Komitesi 1890 yılında Tiflis'te kurulmuş ve Osmanlı Devleti içerisindeki Ermeni olaylarının ortaya çıkmasında diğer Ermeni komiteleri ile birlikte önemli bir rol oynamıştır. Ve hatta zamanla özellikle I. Dünya savaşı arifesinde ve sırasında bu komite Ermeniler üzerinde en etkili rol oynayan komite durumuna gelmiştir. Taşnaksutun hem Rusya hem de Osmanlı Devleti içerisinde aktif bir şekilde örgütlenmiş ve yasal olmayan bir komiteydi.

Taşnaksutun kelime olarak Ermenice federasyon anlamına gelmektedir. Başta Rusya Ermenileri olmak üzere farklı Ermeni grupların bir araya geldikleri bir oluşum olduğundan federasyon ismini kullanmışlardır. Bu Ermeni komitesine Türkçede kısaca "Taşnak" denilmektedir (Gürün 1988, 172-173; Taşnaksutun Komitesi hakkında daha geniş bilgi için bk. Uras 1950; Nalbandian 1963; Agayan 1968, 334- 347; Basiliya 1968; Koçar 1988; Dasnabedian 1989; Lalayan 1990, 82-107; Gaibov 1990; RGİA, Fond: 1405, Op.: 521, Delo: 442, LL.379-395 vd.).

$\mathrm{Bu}$ federasyonu oluşturan gruplardan biri Sosyalist olmayan milliyetçi ihtilalciler olup bunlar Osmanlı Ermenilerinin bağımsızlığı ile ilgilenmekte ve Armenakan partisine yakın kişilerdi. Bunların çoğu Petersburg'da bulunan öğrencilerdi. Bu gruba Tiflis'te toplandıkları pansiyonda kaldıkları yere göre "Severnoye Nomera" denilmekteydi. Federasyondaki sosyalist ihtilalcilerin bir bölümü Rus ve Gürcü ihtilalci gruplarıla birlikte olup Çar rejimini devirmek fikrini savunmaktaydılar. Bir başka sosyalist grup da sadece Osmanlı Ermenileri ile ilgilenmekteydiler. Bunlara da Tiflis'te toplandıkları pansiyonda kaldıkları yere göre "Yujnıye Nomera" denilmiştir. Federasyon içerisinde başka gruplar da bulunmaktaydı (Gürün 1988, 172-173).

Taşnaksütun Komitesi'nin başlangıçta Cenevre'de bulunan gizli bir büro tarafından idare edildiği biliniyor. Bununla birlikte asıl faaliyetlerinin yoğunlaştığ 1 ve ileri gelenlerin bulunduğu yer Tiflis'ti. Dolayısıyla daha ilk kurulduğu yıllardan itibaren bu komite gizli bir ihtilalci örgütlenme olarak Rus makamlarının dikkatini çekmiş ve kovuşturmaya uğramıştır (Gürün 1988, 173).

Taşnaksutun Komitesi'nin 1894 yılında kendi yayın organı olan Droşak dergisinde yayımlanan tüzügüne bakıldığında komitenin amacının, Osmanlı Devleti’nin doğu vilayetlerinde (onlara göre "Türkiye Ermenistanı") siyasî ve ekonomik özgürlük elde etmek olduğu belirtilmiştir. Komitenin bu amaca ulaşmak için savaşçı gruplar oluşturmak ve bu grupları hem ideolojik hem de pratik olarak yetiştirilmeleri, Anadolu'ya insan ve silah sevk edilmesi, çeteler yetiştirilmesi ve bunları faaliyete hazırlanması, halkın silahlandırılması gibi yöntemleri kullanacağı da burada beyan edilmiştir. Komitenin tüzüğünde bulunan bu bilgiler, Taşnaksutun Komitesi'nin kurulduğu andan itibaren çok açık şekilde bir terör örgütü olduğunu göstermektedir (Gürün 1988, 
173; Oganesyan 1991, 81-83).

Taşnaksütun Komitesi, 1892-1895 yılları arasında büyük bir gelişme göstermiş ve yaygınlaşmıştı; Parti, İstanbul, Trabzon, Batum, Hovıy Nahçivan, Tiflis, Bakü, Gandzak, Karabağ'da şubeler kurdu. Bununla birlikte Taşnaksutun Komitesi, Balkanlarda, Misır'da, Kıbrıs'ta, Cenevre'de, Paris'te, Marsilya'da ve 1896 yılı itibari ile de Amerika Birleşik Devletleri'nde komiteler oluşturmuştu. Parti üyelerinin çoğunluğu propaganda ve silahlı mücadele yapmak üzere Anadolu'ya gönderilmişlerdi. Komite aynı zamanda, İran Artpatakan, Surmalu, Kars ve Gümrü'de oluşturulmuş olan stoklardan Anadolu'ya silah sevkiyatını organize ediyordu ve Tebriz'de silah atölyesi kurmuştu. 1895 yılında Rus resmi makamlarının hazırladıkları raporlardan, bu cemiyet üyelerinin aktif bir faaliyet içerisinde oldukları, o dönemde Rusya' daki Ermeni halkı arasında faaliyetlerinin sürdüğünü ve komitenin Osmanlı topraklarına üyelerini gönderdiği anlaşılmaktadır. Ayrıca komitenin bu yıllarda silah almaya devam etmekte olduğu ve 1895 yılında Tula fabrikalarından Ermeniler tarafından Tebriz'e gönderilmek üzere büyük bir miktarda silah alındığı da bu raporlarda yer almaktadır (Doğan 2007, 11).

Taşnaksutun Komitesi'nin bu faaliyetleri zaman içerisinde artarak devam edecek ve yukarıda da belirttiğimiz üzere Ermeni cemiyetleri içerisinde etkili olan en önemli bir komite haline gelecektir. I. Dünya Savaşı'na kadar da başta Rusya ve Osmanlı Devleti topraklarında örgütlenmeye, silahlı terör hareketleri yapmaya, isyanlar çıkarmaya, Ermeni zenginlerine ve din adamlarına suikast gibi birçok terör eyleminde bulunacaktır (Ayrıntılı bilgi için bk. Karacakaya 2016).

Yukarıda anlatıldığı üzere kurulduğu günden itibaren bir terör örgütü olan Taşnaksutun Komitesi Rusya tarafından da takip edilmiş ve üyeleri terör suçu ile tutuklanmıştır. İşte, makalemize konu olan 1912 tarihli Rus Devlet Tarih Arşivi (Rossiyskiy Gosudarstvennıy İstoriçeskiy Arhiv)'nde bulunan bu dosyada Ermeni komitesi Taşnaksutun'un Rusya'da tutuklanmış üyeleri hakkında bilgiler içermekte ve belgede Ermeni İhtilal Komitesi Taşnaksutun İddianamesi Dosyası'nda karşılaşılan şifreli kişi, yer isimleri ve diğer şifreli kelimeler ve deşifresi de verilmektedir. Bu şifreli kelimeler Rus emniyet yetkililerince tespit edilmiş ve Rusya'da yargılanan Taşnaksutun Komitesi üyeleri dosyasında bulunmaktadır. Aynı zamanda bu dosyada birçok Taşnaksutun Komitesi üyesinin adları deşifre edilmekte suç dosyaları bulunmaktadır (RGİA, F.935, Op.1 g. 1912 delo.311).

Komitenin yazışmalarında kullandığı ve Rus resmi kayıtlarına geçmiş olan deşifre edilebilmiş kelimelerin toplam sayısı 41 tanedir. Bu kelimelerin 11 tanesi gizli komite üyelerinin isimleri (Gülhandyan, Mamkonyan, Muradov vb.); 13 tanesi yer ismi (Gence, Moskova, Erivan Bakü vb.); 6 tanesi Komite şubeleri (Astrahan Komitesi, Ahalkelek Komitesi vb.); Kelimelerin diğerleri de Komitenin bomba, jandarma, komite içerisindeki grup isimleri gibi farklı şifreli kelimelerdir. Aşağıda şifreli kelimelerin orijinal yazılışları, Latin harflerine transkripti ve Rus makamlarınca yapılmış olan deşifreleri verilmiştir. Anlamları tespit edilebilen kelimelerin Türkçe anlamları parantez içerisinde normal yazı karakteri ile tarafımızca gösterilmiştir. Belgede kelimelerin yanında düşülmüş notlar ise parantez içerisinde italik olarak gösterilmiştir.

Taşnaksutun Komitesi suç iddianamesi dosyasında bulunan söz konusu şifreli kelimeler ile deşifreleri aşağıdaki gibidir:

Ermeni İhtilal Komitesi Taşnaksutun İddianamesi Dosyasında Karşılaşılan Şifreli Kişi, Yer İsimleri ve Diğer Şifreli Kelimeler ve Deşifresi (RGíA, F.935, Op.1 g. 1912 delo. 311). 


\begin{tabular}{|c|c|c|}
\hline ŞİFRELİ KELIME & TRANSKRIPT & DEŞİFRE \\
\hline Абрам & Abram & Gülhandyan \\
\hline Айгестан & Aygestan & Yelizavetpol (Gümrü) \\
\hline Аксавайрский & Aksavayrskiy & Astrahan Komitesi \\
\hline Анджатаканы & Ancatakanı & Genç Taşnaksutun üyeleri \\
\hline Антарапат & Antarapat & Karakilis (Parti deposunun bulunduğu yer) \\
\hline Апараж & Aparaj & Şuşa Komitesi \\
\hline Apa & Ara & Mamkonyan (Eğitmen) \\
\hline Аршак Турецкий & Arşak Turetskiy & Muradov, Arşak Masakov \\
\hline Аслан & Aslan & Yezikov (Öldürülmüş) \\
\hline Большой Город & Bolşoy Gorod & Tiflis (Büyük şehir anlamına gelmektedir) \\
\hline Восканапад & Voskanapat & Bakü \\
\hline Гохтовайр & Goxtovayr & Kiev (anlaşıldı̆̆ına göre) \\
\hline Джаконский & Cakonskiy & Ahıska Komitesi \\
\hline Детраберд & Detraberd & Kars şehrinde 2. Merkez Komitesi \\
\hline Дяди & Dyadi & Jandarma polisi (Amca demektir) \\
\hline Ергир & Yergir & Türkiye Ermenistanı \\
\hline Жлат & Jlat & Vladikafkas \\
\hline Жлат & Jlat & Nalband Rostov \\
\hline Зинвор & Zinvor & Savaşçı, terörist \\
\hline Зифон & Zifon & Silah alımı ve sevkiyatından sorumlu organ. \\
\hline Кармир-Казак & Karmir-Kazak & Yekaterinodar (Krasnodar) \\
\hline Луйск & Luysk & Bir grubun adi \\
\hline Мардирос & Mardiros & Cezalandırılmış olan \\
\hline Медь & Myed & Dinamit (Türkçe bal anlamındadır) \\
\hline Мирмур & Mirmur & Doktor Muratov (gizlendi ilanla aranıyor) \\
\hline Мишель & Mişel & Cumşud: Melik Şahnazarov Bey \\
\hline Мкрстан & Mkrstan & Erivan \\
\hline Мрурян & Mruryan & Doktor Muratov (gizlendi ilanla aranıyor) \\
\hline Налбанд & Nalband & Nahçivan na Donu \\
\hline Нужег & Nujeg & Ter-Arutyunov, Garegin (suçlanan) \\
\hline Новоангист & Novoangist & Batum \\
\hline Hop & Nor & Avan: Armavir (Serdarabad) \\
\hline $\begin{array}{l}\text { Петербургская } \\
\text { Молочная v в Батуме }\end{array}$ & $\begin{array}{l}\text { Peterburgskaya } \\
\text { Moloçnaya } \\
\text { Batume }\end{array}$ & Petrosyan, Ayrepet Tatevosov (suçlanan) \\
\hline Почтовой ящик но 23 & Poçtovıy yaşik No 23 & Abovyan Levon Vartanov (suçlanan) \\
\hline Сардар & Sardar & Kuzaryants Artemiy Stepanov. \\
\hline Север & Sever & Peterburg (Türkçe Kuzey anlamına gelmektedir) \\
\hline Тумбук & Tumbuk & Ahılkelek Komitesi \\
\hline Хечо & Heço & Haçatur Kevorkov (hükümlü terörist) \\
\hline Хумба & Humba & Taşnaksutun Partisi zinvor birliği. \\
\hline Церков & Tserkov & Moskova (Türkçe Kilise anlamına gelmektedir) \\
\hline Яблоко & Yabloko & Bomba (Türkçe elma anlamına gelmektedir) \\
\hline
\end{tabular}




\section{KAYNAKÇA}

Agayan S. P. (1968). “Armyanskiye Politiçeskiye Partii i Pervaya Mirovaya Voyna”. Pervaya Mirovaya Voyna 1914-1918 (1968) 334-347. Moskva.

Bashanov M. (2013). Türkiye'de Ermeni Meselesi (Rus Genelkurmay Başkanlı̆̆ Belgeleri). Çev. İ. Kemaloğlu. Ankara 2013.

Basilaya Ş. İ. (1968). Zakavkaze v Godı Pervov Mirovoy Voynı. Suhumi 1968.

Dasnabedian H. (1989). History of the Armenian Revolutionary Federation Dashnaksutun (1890-1924). İtaly 1989.

Dilan H. (2005). Fransı Diplomatik Belgelerinde Ermeni Olayları. Ankara 2005.

Doğan Ş. (2007). Rus Kaynaklarına Göre Doğu Anadolu'daki Ermeni Faaliyetleri (1914-1918). Kahramanmaraş 2007.

Gaibov B. (1990). Daşnaki. Baku 1990.

Gürün K. (1988). Ermeni Dosyası. Ankara 1988.

Karacakaya R. (2016). Ermenilere Yönelik Ermeni Terörü. İstanbul 2016.

Koçar M. R. (1988). Armyano-Turetskie Obşsestvenno-Politiçeskie Otnoşeniya i Armyanskiy Vopros $v$ Kontse XIX-Naçale XX Vekov. Yerevan 1988.

Lalayan A. (1990). Kontrrevolutsionnly “Taşnaksütun”i Imperialistiçeskaya Voyna 1914-1918 gg. Baku 1990.

Nalbandian L. (1963). The Armenian Revolutionary Movement. Los Angeles 1963.

Oganesyan E. (1991). Vek Borbı. Moskva 1991.

Sonyel S. R. (2014). Ingiliz Gizli Belgelerine Göre Adana'da Vuku Bulan Türk-Ermeni Olayları (Temmuz 1908-Aralık 1909. Ankara 2014.

Şimşir B. N. (1989-1990). British Documents on Armenians. Ankara 1989-1990.

Uras E. (1950). Tarihte Ermeniler ve Ermeni Meselesi. Ankara 1950.

\section{Arşiv Belgeleri}

RGIA, F. 1405, Op. 521, D. 442.

$R G \dot{I} A$, F.935, Op.1 g. 1912 D. 311. 